\title{
Influência do puerpério sobre o proteinograma sérico de caprinos da raça Saanen obtido por eletroforese em gel de poliacrilamida
}

\author{
Influence of puerperium on the serum proteins of Saanen goats, \\ obtained by the analysis of electrophoresis on sodium dodecyl \\ sulphate-polyacrylamide gel
}

\author{
João Paulo Elsen Saut'; Regiane Machado de Souza²; Daniela Becker Birgel²; \\ Fabio Celidonio Pogliani²; Carolina Zaghi Cavalcante²; Samantha Ive Miyashiro ${ }^{3}$, \\ José Jurandir Fagliari ${ }^{4}$; Eduardo Harry Birgel Junior ${ }^{5 *}$
}

\begin{abstract}
Resumo
Com o objetivo de avaliar a influência do puerpério no proteinograma de caprinos da raça Saanen foram colhidas 108 amostras de soro sangüíneo de 12 cabras, sendo os resultados apresentados em nove momentos: imediatamente após a parição, 1, 3, 5, 7, 10, 15, 21 e 30 dias após o parto. Os teores séricos de proteína total foram determinados pela técnica do biureto, e para o fracionamento das proteínas foi realizada a eletroforese em gel de poliacrilamida contendo dodecil sulfato de sódio (SDS-PAGE). No método utilizado foram observadas 17 bandas protéicas, cujos pesos moleculares (PM) variaram de 25 KDa a $275 \mathrm{KDa}$, sendo possível a identificação das seguintes frações protéicas: imunoglobulina A (180 $\mathrm{KDa})$, ceruloplasmina $(115 \mathrm{KDa})$, transferrina $(79 \mathrm{KDa})$, albumina $(65 \mathrm{KDa})$, imunoglobulina $\mathrm{G}$ cadeia pesada $(58 \mathrm{KDa})$, haptoglobina $(45 \mathrm{KDa})$, glicoproteína ácida $(37 \mathrm{KDa})$ e imunoglobulina $\mathrm{G}$ cadeia leve $(28 \mathrm{KDa})$. As outras 9 frações protéicas não identificadas apresentaram pesos moleculares iguais a 275 $\mathrm{KDa}, 140 \mathrm{KDa}, 125 \mathrm{KDa}, 103 \mathrm{KDa}, 95 \mathrm{KDa}, 41 \mathrm{KDa}, 35 \mathrm{KDa}, 30 \mathrm{Kda}$ e $25 \mathrm{KDa}$. Os resultados obtidos permitem concluir que durante a primeira semana do puerpério ocorre um aumento das concentrações de glicoproteína ácida, enquanto as demais frações protéicas não sofrem influência do puerpério.
\end{abstract}

Palavras-chave: Caprinos, puerpério, proteinograma, eletroforese, SDS-PAGE

\begin{abstract}
Aiming to evaluate the puerperal influence on the proteinogram of Saanen goats, 108 samples of blood serum from 12 goats were collected, and the results were presented at nine times: just after parturition, $1,3,5,7,10,15,21$ and 30 days after parturition. Total amount of serum proteins were determined by the biuret technique, and the sodium dodecyl sulphate-polyacrylamide gel electrophoresis (SDSPAGE) was used to the protein fractionation. In this last method, 17 protein bands were observed, from which molecular weights varied between $25 \mathrm{KDa}$ and $275 \mathrm{KDa}$. In addition, it was possible to identify the following protein fractions: immunoglobulin $\mathrm{A}(180 \mathrm{KDa})$, ceruloplasmin $(115 \mathrm{KDa})$, transferrin
\end{abstract}

1 Pós-graduando em Clínica Veterinária da Faculdade de Medicina Veterinária e Zootecnia da Universidade de São Paulo - FMVZ/ USP. E-mail: jpsaut@usp.br

2 Pós-graduando em Clínica Veterinária da Faculdade de Medicina Veterinária e Zootecnia da Universidade de São Paulo - FMVZ/ USP.

3 Técnica Nível Superior da Faculdade de Medicina Veterinária e Zootecnia da Universidade de São Paulo - FMVZ/USP.

4 Professor livre-docente da Faculdade de Ciências Agrárias e Veterinárias da Universidade Estadual Paulista Júlio de Mesquita Filho - FCAV/UNESP.

5 Professor Associado da Faculdade de Medicina Veterinária e Zootecnia da Universidade de São Paulo - FMVZ/USP.

Autor para correspondência 
(79 KDa), albumin (65 KDa), heavy-chain immunoglobulin G (58 KDa), haptoglobin (45 KDa), acid glycoprotein $(37 \mathrm{KDa})$ and light-chain immunoglobulin $\mathrm{G}(28 \mathrm{KDa})$. Another 9 nonidentified protein fractions presented, each molecular weights equal to $275 \mathrm{KDa}, 140 \mathrm{KDa}, 125 \mathrm{KDa}, 103 \mathrm{KDa}, 95 \mathrm{KDa}$, $41 \mathrm{KDa}, 35 \mathrm{KDa}, 30 \mathrm{Kda}$ and $25 \mathrm{KDa}$. The results allow us to conclude that by the first week of puerperium, an improvement of acid glycoprotein occurs, whereas those others protein fractions do not suffer any puerperal influence.

Key words: Goats, puerperium, proteinogram, electrophoresis, SDS-PAGE

\section{Introdução}

Durante a parição o útero sofre uma intensa contaminação por germes presentes no meio ambiente, sendo que Birgel et al. (2002) relataram que a microbiota presente no útero de cabras Saanen durante o puerpério é composta por uma grande variedade de bactérias. Com o passar das semanas ocorre uma diminuição de fêmeas com infecção uterina, ou seja, com a evolução do puerpério verificase a cura de boa parte dessas infecções em decorrência da ação das defesas orgânicas (GRUNERT et al., 2005). A depuração de bactérias do útero está associada à regeneração e remodelamento tecidual do endométrio, sendo relatado para a espécie bovina e para a caprina a ocorrência de leucograma com leucocitose fisiológica por neutrofilia com desvio à esquerda regenerativo (BIRGEL JUNIOR et al., 2005; SAUT; BIRGEL JUNIOR, 2006).

Além das modificações no leucograma, a importância do proteinograma sérico no monitoramento de várias enfermidades infecciosas e/ou na identificação de focos infecciosos foram destacadas por Fagliari e Silva (2002) que relacionaram as modificações que ocorrem no sítio inflamatório com a liberação de citocinas e a síntese de proteínas de fase aguda.

Segundo Fagliari e Silva (2002) a eletroforese em gel de poliacrilamida contendo dodecil sulfato de sódio (SDS-PAGE), além de ser de fácil execução, baixo custo e necessitar de um volume reduzido de amostra, possibilita a visualização de concentrações protéicas extremamente baixas e a identificação de 20 a 30 proteínas com pesos moleculares que variam entre 24.000 a 340.000 daltons.
A presença de infecções bacterianas uterinas, no pós-parto, pode estimular a síntese de determinadas proteínas de fase aguda de interesse veterinário como o fibrinogênio, a ceruloplasmina, a proteína C-reativa, a antitripsina, a haptoglobina e a glicoproteína ácida (ALSEMGEEST et al., 1993; REGASSA; NOAKES, 1999), sendo que a análise da literatura não evidenciou a existência de pesquisas preocupadas com a avaliação da influência do puerpério no proteinograma dos caprinos.

Diante da carência de pesquisas sobre o assunto, objetivou-se estudar a influência do puerpério fisiológico no proteinograma sérico de cabras da raça Saanen, utilizando-se a técnica de eletroforese em gel de poliacrilamida contendo dodecil sulfato de sódio (SDS-PAGE).

\section{Material e métodos}

$\mathrm{Na}$ presente pesquisa foram utilizadas 12 cabras consideradas clinicamente sadias (parto eutócico e evolução de puerpério fisiológico), mantidas no Centro de Pesquisa e Diagnóstico de Enfermidades de Ruminantes - CPDER - do Departamento de Clínica Médica da Faculdade de Medicina Veterinária e Zootecnia da Universidade de São Paulo. As cabras foram vermifugadas e alimentadas com concentrado, feno e sal mineral, sendo que antes da colheita das amostras realizava-se o exame clínico geral e do aparelho genital. Durante o período experimental foram colhidas amostras de sangue nos momentos a seguir discriminados: imediatamente após a parição, 1, 3, 5, 7, 10, 15, 21 e 30 dias após o parto. 
As amostras de sangue foram colhidas por punção da veiajugular externa, sem garroteamento excessivo do vaso, utilizando-se o Sistema Vacutainer, em tubos de vidro siliconizados sem anticoagulante, providos de tampa de borracha e com vácuo suficiente para aspirar $10 \mathrm{ml}$ de sangue. A seguir, as amostras foram centrifugadas com força real de centrifugação igual a 1000 g, por 15 minutos, para a ocorrência de uma adequada sinérese do coágulo. O soro sangüíneo foi separado, por aspiração, utilizando-se pipetas Pasteur, em alíquotas, acondicionadas em tubos plásticos com capacidade para $3 \mathrm{ml}$, providos de tampas e conservadas em freezer a menos $20^{\circ} \mathrm{C}$ até a realização das provas.

A determinação dos teores séricos de proteína total foi feita pelo método do biureto, de acordo com a técnica preconizada por Gornall, Bardawill e David (1949) e modificada por Strufaldi (1987), com leitura da coloração da reação obtida em espectrofotômetro, utilizando-se comprimento de onda de $550 \mathrm{~nm}$.

Para o fracionamento das proteínas foi realizada a eletroforese em gel de poliacrilamida contendo dodecil sulfato de sódio (SDS-PAGE), conforme a técnica descrita por Laemmli (1970) e as recomendações de Fagliari e Silva (2002). Corouse o gel, mergulhando-o no corante Coomassie Blue $0,2 \%$, durante 20 minutos; sendo o excesso de corante retirado com solução descorante de ácido acético a 7\%. Finalmente, a quantificação da frações foi realizada em densitômetro da Marca Byosistems, modelo Epson Expression 1680, com uso de "software" de análise de imagens VisionWorksLS, da marca Ultra-Violet Products. Para perfeita identificação das frações protéicas do soro sangüíneo foi utilizado, em cada corrida de eletroforese, um marcador padrão de pesos moleculares da marca Invitrogen com bandas entre $10 \mathrm{kDa}$ e $220 \mathrm{kDa}$.

Para a análise estatística, utilizou-se o programa Minitab - versão 14., sendo os dados apresentados em média aritmética, desvio-padrão e mediana. As variáveis, inicialmente, foram submetidas ao Teste de Kolmogorov-Smirnov para verificar se os dados apresentavam ou não distribuição paramétrica. As variáveis com distribuição paramétrica foram submetidas à análise de variância e teste de Tukey. As variáveis com distribuição não-paramétrica foram analisadas pelo teste de Kruskall-Wallis (Anova não-paramétrica) e o teste de Comparação Múltipla de Dunn's. Todos os testes apresentaram níveis de significância igual a $5 \%(\mathrm{p} \leq 0,05)$.

\section{Resultados e discussão}

No método utilizado foram observadas 17 bandas protéicas, cujos pesos moleculares (PM) variaram de $25 \mathrm{KDa}$ a $275 \mathrm{KDa}$, sendo possível a identificação das seguintes frações protéicas: imunoglobulina A (180 KDa), ceruloplasmina (115 KDa), transferrina (79 KDa), albumina (65 KDa), imunoglobulina $\mathrm{G}$ de cadeia pesada $(58 \mathrm{KDa})$, haptoglobina (45 KDa), glicoproteína ácida (37 KDa) e imunoglobulina $\mathrm{G}$ de cadeia leve $(28 \mathrm{KDa})$. As outras nove bandas protéicas não identificadas apresentaram pesos moleculares de $275 \mathrm{KDa}, 140 \mathrm{KDa}, 125 \mathrm{KDa}$, $103 \mathrm{KDa}, 95 \mathrm{KDa}, 41 \mathrm{KDa}, 35 \mathrm{KDa}, 30 \mathrm{KDa}$ e 25 KDa.

Diferentemente do que foi relatado para a espécie bovina, na qual o quadro protéico durante o puerpério era caracterizado por hipoproteinemia em decorrência de hipoalbuminemia e de hipoglobulinemia (BIRGEL JUNIOR et al., 2003; D'ANGELINO et al., 1975) na presente pesquisa o referido fenômeno não foi observado. Demonstrouse que os teores séricos de proteína total (Tabela 2) não foram influenciados pelo puerpério, sendo que nos primeiros 30 dias após o parto os seus valores oscilaram entre $5,70 \pm 0,60 \mathrm{~g} / \mathrm{dl}$ e $6,40 \pm 0,80 \mathrm{~g} / \mathrm{dl}$. Constatou-se, também, que os teores de albumina (Tabela 1) oscilaram entre $2,87 \pm 0,32$ e 3,23 \pm $0,36 \mathrm{~g} / \mathrm{dl}$, sem que qualquer diferença estatística pudesse ser verificada. Em bovinos, as diminuições na produção de albumina pelo fígado durante a fase final da gestação, bem como durante o puerpério foram relacionadas à infiltração de gordura no 
tecido hepático, sendo que na dependência da intensidade desta esteatose hepática, a diminuição na produção de albumina poderia ser de pequena ou grande magnitude (SOUZA, 2005). Apesar de distúrbios do metabolismo lipídico e energético ser freqüentemente diagnosticado na clínica de pequenos ruminantes (ORTOLANI; BENESI, 1989), os resultados da presente pesquisa não evidenciaram em nenhuma das cabras examinadas a ocorrência de hipoalbuminemia. Este fato é indicativo de que, em cabras sadias, a infiltração de gordura no tecido hepático durante o final da gestação e no puerpério é de pequena magnitude.

Da mesma forma que a albumina, não foi observada a influência do puerpério nos teores séricos de Imunoglobulinas (Tabela 2), pois os valores de $\operatorname{IgG}$ de cadeia pesada oscilaram entre $946,1 \pm 287,3$ e $1184 \pm 347 \mathrm{mg} / \mathrm{dl}$, de IgG de cadeia leve oscilaram entre $285,5 \pm 162,9$ e 433,5 $\pm 215,7$ $\mathrm{mg} / \mathrm{dl}$ e de IgA oscilaram entre $124 \pm 62,1$ e 193,1 $\pm 55,7 \mathrm{mg} / \mathrm{dl}$, sem que qualquer diferença estatística fosse detectada. Em bovinos, no dia do parto, há uma abrupta diminuição da concentração de proteína total devido à transferência de globulinas para a glândula mamária e formação do colostro (NATH et al., 2005). Feitosa et al. (2001) comprovaram que a transferência de imunidade nos primeiros momentos de vida do bezerro deve-se, quase que exclusivamente, à absorção de imunoglobulinas presentes no colostro. Esta diminuição já pode ser constatada 14 dias antes do parto e permanece até os sete dias pós-parto em vacas Holandesas (MORAES et al., 1997).

Tabela 1. Teores séricos de proteínas de fase aguda em cabras sadias da raça Saanen durante o puerpério. São Paulo, 2008 .

\begin{tabular}{|c|c|c|c|c|c|}
\hline \multirow[b]{2}{*}{$\begin{array}{c}\text { Dias } \\
\text { após o parto }\end{array}$} & \multicolumn{5}{|c|}{ PROTEÍNAS DE FASE AGUDA (mg/dl) } \\
\hline & $\begin{array}{l}\text { Albumina } \\
\text { (65 KDa) }\end{array}$ & $\begin{array}{l}\text { Ceruloplasmina } \\
\quad(115 \mathrm{KDa})\end{array}$ & $\begin{array}{c}\text { Transferrina } \\
\text { (79 KDa) }\end{array}$ & $\begin{array}{l}\text { Haptoglobina } \\
\text { (45 KDa) }\end{array}$ & $\begin{array}{c}\text { Glicoproteína } \\
\text { ácida } \\
(37 \mathrm{KDa})\end{array}$ \\
\hline $\begin{array}{l}\text { Imediatamente } \\
\text { após o Parto }\end{array}$ & $\begin{array}{c}3012 \pm 381^{\mathrm{a}} \\
(2976)\end{array}$ & $\begin{array}{c}59,5 \pm 33,7 \\
(49)^{a}\end{array}$ & $\begin{array}{c}651,9 \pm 147,3 \\
(656,2)^{a}\end{array}$ & $\begin{array}{c}31,95 \pm 25,89 \\
(20,6)^{\mathrm{a}}\end{array}$ & $\begin{array}{c}40 \pm 95,6 \\
(0)^{\mathrm{ab}}\end{array}$ \\
\hline 1 dia & $\begin{array}{c}2871,6 \pm 320,9^{a} \\
(2794,7)\end{array}$ & $\begin{array}{c}69,1 \pm 46 \\
(56,7)^{\mathrm{a}}\end{array}$ & $\begin{array}{c}628,7 \pm 128,4 \\
(619,1)^{a}\end{array}$ & $\begin{array}{c}16,88 \pm 22,12 \\
(8,28)^{\mathrm{a}}\end{array}$ & $\begin{array}{c}30,35 \pm 33,24 \\
(20,51)^{a}\end{array}$ \\
\hline 3 dias & $\begin{array}{c}3192 \pm 703^{a} \\
(3055)\end{array}$ & $\begin{array}{c}52,53 \pm 20,55 \\
(41,9)^{\mathrm{a}}\end{array}$ & $\begin{array}{c}651,9 \pm 130,7 \\
(661,6)^{a}\end{array}$ & $\begin{array}{c}21,81 \pm 27,65 \\
(7,63)^{a}\end{array}$ & $\begin{array}{c}63,5 \pm 104,4 \\
(20,4)^{a b}\end{array}$ \\
\hline 5 dias & $\begin{array}{c}3193 \pm 514^{\mathrm{a}} \\
(3289)\end{array}$ & $\begin{array}{c}55,4 \pm 34 \\
(47,3)^{\mathrm{a}}\end{array}$ & $\begin{array}{c}646 \pm 126,7 \\
(638,2)^{\mathrm{a}}\end{array}$ & $\begin{array}{c}25,2 \pm 34,3 \\
(12,3)^{a}\end{array}$ & $\begin{array}{c}36,4 \pm 61,9 \\
(20,9) \text { ac }\end{array}$ \\
\hline 7 dias & $\begin{array}{c}3094 \pm 369^{a} \\
(3137)\end{array}$ & $\begin{array}{c}60,7 \pm 46,9 \\
(35,6)^{\mathrm{a}}\end{array}$ & $\begin{array}{c}632,8 \pm 164,5 \\
(632,3)^{a}\end{array}$ & $\begin{array}{c}32,55 \pm 31,4 \\
(21,06)^{a}\end{array}$ & $\begin{array}{c}42,6 \pm 60,8 \\
(7,49)^{a b}\end{array}$ \\
\hline 10 dias & $\begin{array}{c}3227 \pm 358^{\mathrm{a}} \\
(3199)\end{array}$ & $\begin{array}{c}54,3 \pm 34,3 \\
(44,0)^{\mathrm{a}}\end{array}$ & $\begin{array}{c}591,5 \pm 147 \\
(585,3)^{\mathrm{a}}\end{array}$ & $\begin{array}{c}22,56 \pm 19,58 \\
(15,83)^{a}\end{array}$ & $\begin{array}{c}10,21 \pm 18,18 \\
(0)^{\text {bc }}\end{array}$ \\
\hline 15 dias & $\begin{array}{c}3023 \pm 422^{a} \\
(3045)\end{array}$ & $\begin{array}{c}68,6 \pm 42,9 \\
(60,4)^{a}\end{array}$ & $\begin{array}{c}614,3 \pm 154,7 \\
(598,4)^{a}\end{array}$ & $\begin{array}{c}29,43 \pm 30,95 \\
(18,59)^{a}\end{array}$ & $\begin{array}{c}8,12 \pm 19,25 \\
(0)^{\mathrm{b}}\end{array}$ \\
\hline 21 dias & $\begin{array}{c}2965 \pm 532^{\mathrm{a}} \\
(2976)\end{array}$ & $\begin{array}{c}50,4 \pm 38,5 \\
(31,3)^{a}\end{array}$ & $\begin{array}{c}687,2 \pm 129,7 \\
(685)^{a}\end{array}$ & $\begin{array}{c}33,9 \pm 29,9 \\
(22,5)^{\mathrm{a}}\end{array}$ & $\begin{array}{c}2,52 \pm 4,88 \\
(0)^{\mathrm{b}}\end{array}$ \\
\hline 30 dias & $\begin{array}{c}3166 \pm 428^{a} \\
(3179)\end{array}$ & $\begin{array}{c}67,9 \pm 44,2 \\
(53,4)^{\mathrm{a}}\end{array}$ & $\begin{array}{c}589,1 \pm 119,3 \\
(523,4)^{a}\end{array}$ & $\begin{array}{c}22,35 \pm 18,6 \\
(19,46)^{a}\end{array}$ & $\begin{array}{c}9,35 \pm 22,94 \\
(0)^{\mathrm{b}}\end{array}$ \\
\hline
\end{tabular}

Nota: Letras diferentes indicam que há diferença estatística $(\mathrm{p}<0,05)$ nas colunas ( ) - mediana 
Tabela 2. Teores séricos de proteína total e de imunoglobulinas em cabras sadias da raça Saanen durante o puerpério. São Paulo, 2008.

\begin{tabular}{|c|c|c|c|c|}
\hline \multirow{2}{*}{$\begin{array}{c}\text { Dias } \\
\text { após o parto }\end{array}$} & \multirow{2}{*}{$\begin{array}{c}\text { PROTEÍNA } \\
\text { TOTAL } \\
\text { (g/dl) }\end{array}$} & \multicolumn{3}{|c|}{ IMUNOGLOBULINAS (mg/dl) } \\
\hline & & $\begin{array}{c}\operatorname{IgA} \\
(180 \mathrm{KDa})\end{array}$ & $\begin{array}{l}\text { IgG cadeia pesada } \\
\quad(58 \mathrm{KDa})\end{array}$ & $\begin{array}{l}\text { IgG cadeia leve } \\
\text { (28 KDa) }\end{array}$ \\
\hline $\begin{array}{l}\text { Imediatamente } \\
\text { após o Parto }\end{array}$ & $\begin{array}{l}6,02 \pm 0,59^{a} \\
(5,87)\end{array}$ & $\begin{array}{l}124 \pm 62,1 \\
(97)^{\mathrm{a}}\end{array}$ & $\begin{array}{c}1001,1 \pm 306,9 \\
(964,1)^{\mathrm{a}}\end{array}$ & $\begin{array}{c}383,3 \pm 137,7 \\
(369,5)^{\mathrm{a}}\end{array}$ \\
\hline 1 dia & $\begin{array}{c}5,66 \pm 0,58^{\mathrm{a}} \\
(5,62)\end{array}$ & $\begin{array}{c}149,4 \pm 98,8 \\
(114,5)^{\mathrm{a}}\end{array}$ & $\begin{array}{c}946,1 \pm 287,3 \\
(1024,2)^{\mathrm{a}}\end{array}$ & $\begin{array}{c}285,5 \pm 162,9 \\
(253,8)^{\mathrm{a}}\end{array}$ \\
\hline 3 dias & $\begin{array}{l}6,20 \pm 0,73^{a} \\
\quad(6,21)\end{array}$ & $\begin{array}{c}140 \pm 73,6 \\
(122,1)^{\mathrm{a}}\end{array}$ & $\begin{array}{c}1071 \pm 338 \\
(980)^{\mathrm{a}}\end{array}$ & $\begin{array}{c}293 \pm 168,5 \\
(268,4)^{\mathrm{a}}\end{array}$ \\
\hline 5 dias & $\begin{array}{l}6,25 \pm 0,71^{\mathrm{a}} \\
\quad(5,98)\end{array}$ & $\begin{array}{c}137,9 \pm 54,2^{a} \\
(124,6)^{a}\end{array}$ & $\begin{array}{c}1115 \pm 367 \\
(1116)^{\mathrm{a}}\end{array}$ & $\begin{array}{c}315,3 \pm 174,2 \\
(216,7)^{\mathrm{a}}\end{array}$ \\
\hline 7 dias & $\begin{array}{r}6,35 \pm 0,65^{\mathrm{a}} \\
(6,31)\end{array}$ & $\begin{array}{c}155,9 \pm 63,1 \\
(136,1)^{\mathrm{a}}\end{array}$ & $\begin{array}{c}1184 \pm 347 \\
(1071)^{\mathrm{a}}\end{array}$ & $\begin{array}{c}354,9 \pm 204,7 \\
(280,9)^{\mathrm{a}}\end{array}$ \\
\hline 10 dias & $\begin{array}{l}6,34 \pm 0,69^{a} \\
\quad(6,32)\end{array}$ & $\begin{array}{c}146,6 \pm 47 \\
(137,6)^{\mathrm{a}}\end{array}$ & $\begin{array}{c}1132 \pm 382 \\
(953)^{\mathrm{a}}\end{array}$ & $\begin{array}{c}373,8 \pm 199,6 \\
(323,7)^{\mathrm{a}}\end{array}$ \\
\hline 15 dias & $\begin{array}{l}6,27 \pm 0,69^{a} \\
\quad(6,13)\end{array}$ & $\begin{array}{c}162,9 \pm 64,2 \\
(152,2)^{\mathrm{a}}\end{array}$ & $\begin{array}{l}1114,6 \pm 331,2 \\
(1007)^{\mathrm{a}}\end{array}$ & $\begin{array}{c}433,5 \pm 215,7 \\
\quad(382,5)^{\mathrm{a}}\end{array}$ \\
\hline 21 dias & $\begin{array}{l}6,27 \pm 1,02^{a} \\
\quad(6,34)\end{array}$ & $\begin{array}{c}162,9 \pm 64 \\
(166,2)^{\mathrm{a}}\end{array}$ & $\begin{array}{l}1168 \pm 402 \\
(1175)^{\mathrm{a}}\end{array}$ & $\begin{array}{l}480,2 \pm 261,6 \\
(395,1)^{\mathrm{a}}\end{array}$ \\
\hline 30 dias & $\begin{array}{c}6,41 \pm 0,80^{a} \\
(6,32)\end{array}$ & $\begin{array}{c}193,1 \pm 55,7 \\
(192,5)^{\mathrm{a}}\end{array}$ & $\begin{array}{c}1122 \pm 333,4 \\
(1027,5)^{\mathrm{a}}\end{array}$ & $\begin{array}{c}414,9 \pm 288,9 \\
(366,7)^{\mathrm{a}}\end{array}$ \\
\hline
\end{tabular}

Nota: Letras semelhantes indicam que não há diferença estatística $(\mathrm{p}<0,05)$ nas colunas

( ) - mediana

Uma diminuição dos teores séricos de albumina, também, foi observada em bovinos com endometrites ou retenções de secundinas (SOUZA, 2005). Nessa situação as alterações do proteinograma poderiam estar relacionadas como parte da resposta de fase aguda, uma vez que a albumina é considerada uma proteína de fase aguda negativa, ou seja, ocorre um desvio em sua síntese quando o fígado é requisitado para a produção de outras proteínas, tais como as proteínas de fase aguda, ou em decorrência de distúrbios hepáticos (JAIN, 1989; KANEKO; HARVEY; BRUSS, 1997). A resposta das proteínas de fase aguda poderia estar presente mesmo durante o processo fisiológico de involução uterina, pois Saut e Birgel Junior (2006) demonstraram que durante o puerpério fisiológico, no sangue dos bovinos, ocorria significativa leucocitose por neutrofilia. Deve ser ressaltado que segundo Birgel Junior et al. (2005) a leucocitose por neutrofilia, em caprinos, é menos intensa e menos duradoura do que a observada em bovinos, evidenciando ser a resposta das proteínas de fase aguda menos intensa nos caprinos.

A maioria das proteínas de fase aguda são glicoproteínas sintetizadas pelos hepatócitos como conseqüência a uma lesão, traumatismo ou infecção tecidual (BAULMANN; GAULDIE, 1994) e são consideradas os indicadores mais fiéis da resposta sistêmica frente aos processos inflamatórios e infecciosos, quando comparadas a outras variáveis, tais como febre, aumento da taxa de sedimentação e/ou presença de leucograma com leucocitose associado à neutrofilia (JAIN, 1989). De modo geral, o estímulo à síntese destas proteínas de fase aguda ocorre 6 a 8 horas após a lesão, sendo que a concentração máxima é alcançada em 2 a 5 dias. Porém, a taxa máxima e a persistência das concentrações plasmáticas destas proteínas dependem do metabolismo, extravasamento 
vascular e deposição tecidual (JAIN, 1993). Não foram encontrados, na literatura consultada, estudos referentes ao comportamento das proteínas de fase aguda no período pós-parto de cabras que pudessem ser utilizados para comparação com os resultados obtidos na presente pesquisa.

A análise estatística dos traçados protéicos obtidos identificou variação significante, entre os momentos, apenas para a banda da glicoproteína ácida (Figura 1). Entre o primeiro e quinto dia após o parto observou-se o aumento dos teores séricos de glicoproteína ácida, sendo que neste período os resultados medianos variaram entre 20,4 e 20,9 $\mathrm{mg} / \mathrm{dl}$. A seguir, a partir do sétimo dia após o parto verificou-se a diminuição dos teores séricos de glicoproteína ácida. Para as demais proteínas de fase aguda avaliadas (Tabela 1), verificou-se que os seus valores medianos oscilaram conforme a seguir discriminado: ceruloplasmina entre 31,3 e $56,7 \mathrm{mg} / \mathrm{dl}$; transferrina entre 523,4 e $685 \mathrm{mg} / \mathrm{dl}$; e, haptoglobina entre 8,28 e $22,5 \mathrm{mg} / \mathrm{dl}$.

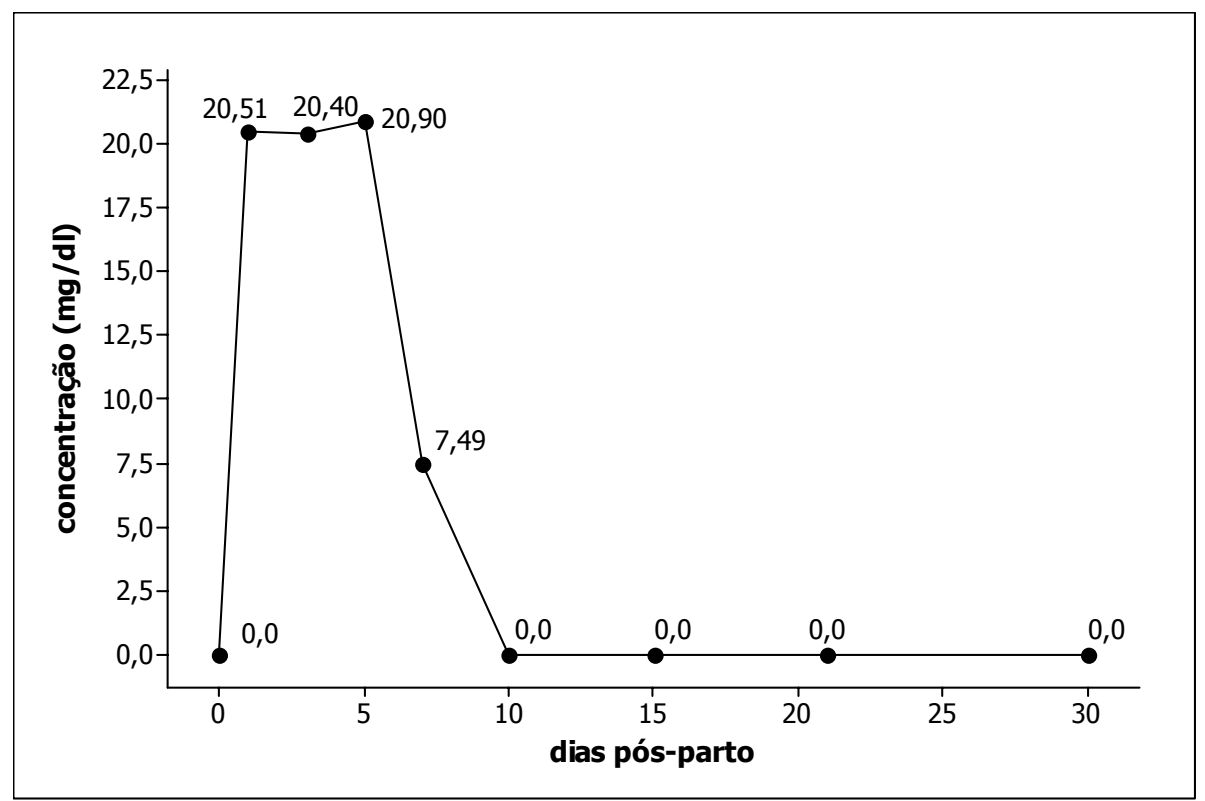

Figura 1. Influência do puerpério nos teores séricos de glicoproteína ácida de caprinos sadios, da raça Saanen, criados no Estado de São Paulo. São Paulo, 2008.

A concentração sérica de glicoproteína ácida altera-se significativamente após um processo inflamatório (CONNER et al., 1989), sendo relatado um significativo aumento nos seus valores em quadros de broncopneumonia induzidos em bezerros inoculados com Mannheimia haemolytica (FAGLIARI et al., 2003) e de mastite em novilhas gestantes (HIRVONEN; PYORALA; JOUSIMIESSOMER, 1996). À semelhança do que foi observado na presente pesquisa, relatou-se o aumento da glicoproteína ácida no puerpério fisiológico de bovinos, sendo que nesta espécie animal o retorno aos patamares de normalidade ocorria tardiamente, somente a partir do $21^{\circ}$ dia pós-parto (SHELDON et al., 2001).

Apesar de Regassa e Noakes (1999) descreverem o significativo aumento dos teores séricos de haptoglobina no primeiro dia após o parto em ovelhas, justificando tal aumento devido ao efeito da PGF $_{2 \alpha}$ que estimularia a secreção de haptoglobina (SHIM, 1976), este fato não foi observado na presente pesquisa. Em relação aos teores séricos de ceruloplasmina, os resultados da pesquisa de Regassa e Noakes (1999) foram semelhantes aos 
obtidos nesta pesquisa para caprinos, sendo que isto ocorreu, provavelmente, pelo fato de não haver estímulo da sua síntese pela parição e pela involução normal do útero.

Além das proteínas de fase aguda, a identificação de outras frações protéicas presentes no plasma ou no soro sangüíneo torna-se útil como indicador do estado de sanidade e/ou imunológico dos animais (PASSOS, 2004). Foram apresentadas na Tabela 3 as proteínas que não puderam ser identificadas e cujos pesos moleculares variavam entre 275 e 25 KDa.

Tabela 3. Teores séricos das frações protéicas não identificadas em cabras sadias da raça Saanen durante o puerpério. São Paulo, 2008.

\begin{tabular}{|c|c|c|c|c|c|c|c|c|c|}
\hline $\begin{array}{c}\text { Grupos } \\
\text { Experimentais } \\
\text { (dias após o parto) }\end{array}$ & \multicolumn{9}{|c|}{ Peso molecular das frações protéicas não identificadas (mg/dl) } \\
\hline $\begin{array}{l}\text { Imediatamente } \\
\text { após o Parto }\end{array}$ & $\begin{array}{c}19 \pm 15,5 \\
(14)^{a}\end{array}$ & $\begin{array}{c}11,4 \pm 8,0 \\
(13)^{\mathrm{a}}\end{array}$ & $\begin{array}{c}62,8 \pm 37,3 \\
(45)^{a}\end{array}$ & $\begin{array}{c}35,8 \pm 25,9 \\
(24)^{a}\end{array}$ & $\begin{array}{c}20,9 \pm 9,0^{\mathrm{a}} \\
(22,3)\end{array}$ & $\begin{array}{c}26,5 \pm 18,5 \\
(17,1)^{a}\end{array}$ & $\begin{array}{c}11,1 \pm 11,4 \\
(9,5)^{\text {a }}\end{array}$ & $\begin{array}{c}103,5 \pm 51,1 \\
(103,2)^{\mathrm{a}}\end{array}$ & $\begin{array}{c}386,3 \pm 133 \\
(374,6)^{a}\end{array}$ \\
\hline 1 dia & $\begin{array}{c}19,9 \pm 11,7 \\
(17,1)^{a}\end{array}$ & $\begin{array}{c}14,4 \pm 6,8 \\
(13,49)^{\mathrm{a}}\end{array}$ & $\begin{array}{c}68,7 \pm 33,1 \\
(78)^{a}\end{array}$ & $\begin{array}{c}42 \pm 31,78 \\
(36,09)^{a}\end{array}$ & $\begin{array}{c}18,9 \pm 7,3^{a} \\
(18,37)\end{array}$ & $\begin{array}{c}16,8 \pm 15,4 \\
(11,3)^{a}\end{array}$ & $\begin{array}{c}3,9 \pm 9,74 \\
(0)^{\mathrm{a}}\end{array}$ & $\begin{array}{c}85,4 \pm 63,7 \\
(73,5)^{a}\end{array}$ & $\begin{array}{c}344,6 \pm 111 \\
(327,4)^{a}\end{array}$ \\
\hline 3 dias & $\begin{array}{c}19,0 \pm 19,2 \\
(14,92)^{a}\end{array}$ & $\begin{array}{c}15,5 \pm 11,3 \\
(15,55)^{a}\end{array}$ & $\begin{array}{c}77,5 \pm 50,9 \\
(59,1)^{a}\end{array}$ & $\begin{array}{c}46,4 \pm 35 \\
(37,2)^{\mathrm{a}}\end{array}$ & $\begin{array}{c}15,9 \pm 10,2^{\mathrm{a}} \\
(14,92)\end{array}$ & $\begin{array}{c}22,6 \pm 17,6 \\
(15,27)^{a}\end{array}$ & $\begin{array}{c}4,6 \pm 9,7 \\
(0)^{\mathrm{a}}\end{array}$ & $\begin{array}{c}113,2 \pm 71,2 \\
(117,5)^{a}\end{array}$ & $\begin{array}{c}346,1 \pm 139 \\
(307,6)^{\mathrm{a}}\end{array}$ \\
\hline 5 dias & $\begin{array}{c}15,9 \pm 13,6 \\
(10,42)^{a}\end{array}$ & $\begin{array}{c}13,0 \pm 11,7 \\
(6,67)^{\mathrm{a}}\end{array}$ & $\begin{array}{c}70,6 \pm 46 \\
(54,2)^{\mathrm{a}}\end{array}$ & $\begin{array}{c}47 \pm 34,5 \\
(34,4)^{a}\end{array}$ & $\begin{array}{c}14,4 \pm 9,85^{\mathrm{a}} \\
(11,89)\end{array}$ & $\begin{array}{c}23,2 \pm 16,6 \\
(18,76)^{a}\end{array}$ & $\begin{array}{c}8,0 \pm 13,1 \\
(0)^{\mathrm{a}}\end{array}$ & $\begin{array}{c}127,9 \pm 82,5 \\
(100)^{\mathrm{a}}\end{array}$ & $\begin{array}{c}367,1 \pm 116 \\
(347,1)^{\mathrm{a}}\end{array}$ \\
\hline 7 dias & $\begin{array}{c}16,7 \pm 15,3 \\
(10)^{a}\end{array}$ & $\begin{array}{c}14,6 \pm 11,1 \\
(12,37)^{\mathrm{a}}\end{array}$ & $\begin{array}{c}80,9 \pm 45,7 \\
(83,4)^{a}\end{array}$ & $\begin{array}{c}45,4 \pm 36,6 \\
(41,4)^{a}\end{array}$ & $\begin{array}{c}14,2 \pm 8,42^{\mathrm{a}} \\
(12,37)\end{array}$ & $\begin{array}{c}31,1 \pm 21,1 \\
(26,33)^{a}\end{array}$ & $\begin{array}{c}14,2 \pm 19,6 \\
(5,05)^{\mathrm{a}}\end{array}$ & $\begin{array}{c}150,5 \pm 94,4 \\
(126,8)^{\mathrm{a}}\end{array}$ & $\begin{array}{c}368,5 \pm 133 \\
(325,5)^{\mathrm{a}}\end{array}$ \\
\hline 10 dias & $\begin{array}{c}11,6 \pm 12,3 \\
(5,41)^{a}\end{array}$ & $\begin{array}{c}12,6 \pm 10,5 \\
(7,02)^{a}\end{array}$ & $\begin{array}{c}73,3 \pm 51,6 \\
(47)^{a}\end{array}$ & $\begin{array}{c}51,6 \pm 33,9 \\
(52,9)^{\mathrm{a}}\end{array}$ & $\begin{array}{c}14,4 \pm 9,09^{\mathrm{a}} \\
(10,82)\end{array}$ & $\begin{array}{c}26,3 \pm 17,5 \\
(22,84)^{a}\end{array}$ & $\begin{array}{c}11,7 \pm 13,3 \\
(9,52)^{\mathrm{a}}\end{array}$ & $\begin{array}{c}133,6 \pm 84,4 \\
(138,2)^{a}\end{array}$ & $\begin{array}{c}408,2 \pm 132 \\
(353,9)^{\mathrm{a}}\end{array}$ \\
\hline 15 dias & $\begin{array}{c}12,2 \pm 13,6 \\
(6,07)^{a}\end{array}$ & $\begin{array}{c}12,5 \pm 9,38 \\
(10,18)^{a}\end{array}$ & $\begin{array}{c}66,9 \pm 43,4 \\
(56,1)^{a}\end{array}$ & $\begin{array}{c}52,5 \pm 31,2 \\
(44,74)^{\mathrm{a}}\end{array}$ & $\begin{array}{c}14,5 \pm 7,57^{a} \\
(11,42)\end{array}$ & $\begin{array}{c}34,0 \pm 20,7 \\
(24,93)^{a}\end{array}$ & $\begin{array}{c}22,3 \pm 22,2 \\
(12,71)^{a}\end{array}$ & $\begin{array}{c}130 \pm 77,1 \\
(110,9)^{a}\end{array}$ & $\begin{array}{c}423,5 \pm 160 \\
(385,8)^{\mathrm{a}}\end{array}$ \\
\hline 21 dias & $\begin{array}{c}15,0 \pm 13,3 \\
(14,11)^{a}\end{array}$ & $\begin{array}{c}12,2 \pm 5,3 \\
(12,07)^{\mathrm{a}}\end{array}$ & $\begin{array}{c}61,9 \pm 43,4 \\
(51,9)^{a}\end{array}$ & $\begin{array}{c}53,4 \pm 28,2 \\
(57,49)^{\mathrm{a}}\end{array}$ & $\begin{array}{c}17,7 \pm 5,57^{a} \\
(18,71)\end{array}$ & $\begin{array}{c}37,7 \pm 31,8 \\
(23,9)^{a}\end{array}$ & $\begin{array}{c}15,4 \pm 18,2 \\
(9,54)^{a}\end{array}$ & $\begin{array}{c}105,8 \pm 78,9 \\
(79,9)^{a}\end{array}$ & $\begin{array}{c}360,6 \pm 155 \\
(307,7)^{\mathrm{a}}\end{array}$ \\
\hline 30 dias & $\begin{array}{c}12,8 \pm 12,2 \\
(8,59)^{\mathrm{a}}\end{array}$ & $\begin{array}{l}12 \pm 6,5 \\
(11,02)^{a}\end{array}$ & $\begin{array}{c}62,5 \pm 32,6 \\
(55,82)^{a}\end{array}$ & $\begin{array}{c}52,8 \pm 29,1 \\
(43,52)^{a}\end{array}$ & $\begin{array}{c}17,2 \pm 5,76^{\mathrm{a}} \\
(16,73)\end{array}$ & $\begin{array}{c}22,8 \pm 14,2 \\
(19,56)^{a}\end{array}$ & $\begin{array}{c}11,6 \pm 11,1 \\
(9,04)^{\mathrm{a}}\end{array}$ & $\begin{array}{c}117,7 \pm 90 \\
(125,5)^{\mathrm{a}}\end{array}$ & $\begin{array}{c}468,8 \pm 139 \\
(476,6)^{a}\end{array}$ \\
\hline
\end{tabular}

Nota: Letras semelhantes indicam que não há diferença estatística $(\mathrm{p}<0,05)$ nas colunas ( ) - mediana

\section{Conclusões}

Os resultados obtidos permitem concluir que durante a primeira semana do puerpério de caprinos ocorre um aumento das concentrações de glicoproteína ácida, enquanto as demais frações protéicas não sofrem influência do puerpério.

\section{Referências}

ALSEMGEEST, S.P.; TAVERNE, M.A. M.; BOOSMAN, R.; VAN DER WEYDEN, B. C.; GRUYS, E. Peripartum acute-phase protein serum amyloid-A concentration in plasma of cows and fetuses. American Journal of Veterinary Research, Chicago, v. 54, n. 11, p. 164-167, 1993.

BAULMANN, H; GAULDIE, J. The acute phase response. Immunology Today, Cambridge, v. 15, n. 2, p. 74-80, 1994. 
BIRGEL JUNIOR, E. H.; NEVES, F. S.; SALVATORE, L. C. A; MIRANDOLA, R. M.; TÁVORA, J. P. F.; BIRGEL, E. H. Avaliação da influência da gestação e do puerpério sobre a função hepática de bovinos da raça Holandesa. Ars Veterinária, Jaboticabal, v. 19, n. 2, p. 172-178, 2003.

BIRGEL JUNIOR, E. H.; VIANA, R. B; AYRES, M. C. C.; BENESI, F. J.; GOMES, V.; BIRGEL, E. H. Influência da parição e do puerpério sobre leucograma de caprinos Capra hircus da raça Saanen, criados no Estado de São Paulo. Brazilian Journal of Veterinary Research and Animal Science, São Paulo, v. 42, n. 5, p. 347-356, 2005.

BIRGEL, E. H.; ROSENFELD, A. F.; BIRGEL JUNIOR, E. H.; LIBERA, A. M. M. P. D.; AYRES, M. C. C. Avaliation of microbiota of uterus during pos-partum of Saanen goats. In: BIRGEL, E. H. ; ROSENFELD, A. M. F. ; BIRGEL JUNIOR, E. H. ; DELLA LIBERA, A. M. M. P. ; AYRES, M.C.C. . Avaliation of microbiota of uterus during postpartum of Saanen goats. In: XXII World Buiatrics Congress, 2002, Hannover. XXII World Buiatrics Congress, 2002. v. 1. p. 197-197.

CONNER, J.; ECKERSALL, P. D.; WISEMAN, A.; BAIN, R. K.; DOUGLAS, T. A. Acute phase response in calves following infection with Pasteurella haemolytica, Ostertagia ostertagi and endotoxin administration. Research in Veterinary Science, London, v. 47, n. 2, p. 203-207, 1989.

D'ANGELINO, J. L.; ARAUJO, L. M.; BIRGEL, E. H.; REICHMANN, C. E.; ARAUJO, W. P. Influência da gestação e do puerpério sobre o proteinograma sangüíneo de bovinos da raça Holandesa Branca e Preta. Revista da Faculdade de Medicina Veterinária e Zootecnia da Universidade de São Paulo, São Paulo, v. 12, p. 197-204, 1975.

FAGLIARI, J. J.; SILVA, S. L. Hemograma e proteinograma plasmático de eqüinos hígidos acometidos por abdômen agudo, antes e após laparotomia. Arquivo Brasileiro de Medicina Veterinária e Zootecnia, Belo Horizonte, v. 54, n. 6, p. 559-586, 2002.

FAGLIARI, J. J.; WEISS, D. J.; MCCLENANHAN, D.; EVANSON, O. A. Serum protein concentrations in calves with experimentally induced pneumonic pasteurellosis. Arquivo Brasileiro de Medicina Veterinária e Zootecnia, Belo Horizonte, v. 55, n. 4, p. 383-387, 2003.

FEITOSA, F. L. F.; BIRGEL, E. H.; MIRANDOLA, R. M. S.; PERRI, S. H. V. Proteinograma sérico de bezerros holandeses do nascimento até um ano de vida. Revista Brasileira de Ciência Veterinária, Niterói, v. 8, n. 2, p. 105-108, 2001.
GORNALL, A. G.; BARDAWILL, C. J.; DAVID, M. M. Determination of serum proteins by means of biuret reaction. The Journal of Biological Chemistry, Bethesda, v. 177, n. 2, p. 751-766, 1949.

GRUNERT, E.; BIRGEL. E. H.; VALE, W. G.; BIRGEL JUNIOR, E. H. Patologia e clínica da reprodução dos animais mamiferos: ginecologia. São Paulo: Varela, 2005.

HIRVONEN, J.; PYORALA, S.; JOUSIMIES-SOMER, $\mathrm{H}$. Acute phase response in heifers with experimentally induced mastitis. Journal of Dairy Research, Cambridge, v. 63, n. 3, p. 351-360, 1996.

JAIN, N. C. Acute phase protein. In: KIRK, R. W. Current veterinary therapy: small animal practice. Philadelphia: Saunders, 1989. p. 468-471.

JAIN, N. C. Essentials of veterinary hematology. Philadelphia: Lea \& Febiger, 1993.

KANEKO, J. J.; HARVEY, J. W.; BRUSS, M. L. Clinical biochemistry of domestic animals. 5. ed. San Diego: Academic Press, 1997.

LAEMMLI, U. K. Cleavage of structural proteins during the assembly of the head of bacteriophage $\mathrm{T}_{4}$. Nature, London, v. 227, n. 15, p. 680-685, 1970.

MORAES, M. P.; WEIBLEN, R.; SILVA, A. M.; TOBIAS F. L. Evolução da imunidade passiva em fêmeas bovinas da raça Holandesa. Ciência Rural, Santa Maria, v. 27, n. 3, p. 435-440, 1997.

NATH, H. C.; BARUAH, K. K.; BARUAH, A.; SARMAH, H. D.; SARMAH, B. C. Serum cholesterol and protein in pre, peri and postpartum cows. Indian Veterinary Journal, Madras, v. 82, n. 5, p. 519-521, 2005.

ORTOLANI, E. L; BENESI, F. J. Ocorrência de Toxemia da Prenhez em cabras (Capra hircus.L) e ovelhas (Ovis aries.L) criadas no estado de São Paulo, Brasil. Revista da Faculdade de Medicina Veterinária e Zootecnia da Universidade de São Paulo, São Paulo, v. 26, n. 2, p. 229-234, 1989.

PASSOS, C. B. Infecção experimental em ovinos com Trypanosoma evansi (Steel, 1885) (Sarcomastigophora: Trypanomatidae). 2004. Tese (Doutorado em Clínica Médica Veterinária) - Faculdade de Ciências Agrárias e Veterinárias, Universidade Estadual Paulista, Jaboticabal.

REGASSA, F.; NOAKES, D. E. Acute phase protein response of ewes and the release of PGFM in relation to uterine involution and the presence of intrauterine bacteria. Veterinary Record, London, v. 144, n. 18, p. 502-506, May 1999. 
SAUT, J. P. E.; BIRGEL JUNIOR, E. H. Influência do período pós-parto sobre o leucograma de fêmeas bovinas da raça Holandesa. Brazilian Journal of Veterinary Research and Animal Science, São Paulo, v. 43, n. 5, p. 588-597, 2006.

SHELDON, I. M.; NOAKES, D. E.; RYCROFT, H.; DOBSON, H. Acute phase protein responses to uterine bacterial contamination in cattle after calving. Veterinary Record, London, v. 148, n. 6, p. 172-175, 2001.

SHIM, B. S. Increase in serum haptoglobin stimulation by prostaglandins. Nature, v. 259, p. 326-327, 1976.
SOUZA, R. M. Avaliação da função hepática e do lipidograma no período puerperal e pós-puerperal e suas inter-relações com os distúrbios reprodutivos de fêmeas bovinas da raça Holandesa, criadas no Estado de São Paulo. 2005. Dissertação. (Mestrado em Clínica Veterinária) - Faculdade de Medicina Veterinária e Zootecnia, Universidade de São Paulo, São Paulo, 2005.

STRUFALDI, B. Prática de bioquímica clínica. São Paulo: Ed. da FCF/USP, 1987. 
